\title{
Reconsiderando el papel de Rafael Reyes en la modernización urbana de Bogotá, 1904-1909
}

Reconsidering the role of Rafael Reyes in the urban modernization of Bogotá, 1904-1909

\author{
Reconsiderando o papel de Rafael Reyes na modernização urbana de \\ Bogotá, 1904-1909
}

\author{
Adriana María Suárez Mayorga² \\ Archivo de Bogotá. Bogotá, D.C., Colombia \\ amsuarezm@yahoo.com
}

Recibido: $30 / 01 / 2017$

Aprobado: 25/04/2017

\begin{abstract}
Resumen
El propósito del artículo es reconsiderar el papel cumplido por el presidente Rafael Reyes (1904-1909) en el proceso de modernización urbana de Bogotá, a la luz de lo sucedido en esos años en el seno de la administración local. Metodológicamente, el análisis se fundamentará en un examen de fuentes primarias y secundarias con el fin de comprender lo ocurrido en la ciudad desde una perspectiva multidimensional, es decir, correlacionando los cambios experimentados en materia urbanística con los factores políticos, económicos y sociales que permearon esa realidad. La conclusión principal a la que se llegó es que el centralismo dictatorial, instaurado durante el Quinquenio, subordinó la administración municipal bogotana a los intereses del poder central. Tal situación generó que en la época se emprendiera una lucha por la autonomía local que fue utilizada por la oposición para desprestigiar al régimen y propiciar la salida de Rafael Reyes al exilio.
\end{abstract}

Palabras clave: Colombia; historiografía; modernización; administración municipal; Rafael Reyes.

\section{Abstract}

The purpose of the article is to reconsider the role played by President Rafael Reyes (19041909) in the process of urban modernization of Bogotá, considering what happened in those years in the local administration. Methodologically, the analysis is based on an examination of primary and secondary sources to understand what happened in the city from a multidimensional perspective; correlating the changes experienced in urban matters with the

\footnotetext{
${ }^{1}$ El presente artículo de reflexión tiene su origen en la investigación llevada a cabo para la tesis doctoral titulada Bogotá en la lógica de la Regeneración. Indagando sobre el papel cumplido por el municipio en la conformación del Estado nacional a partir del análisis de la administración capitalina, 1886-1910, la cual fue sustentada en el 2015 en la Facultad de Ciencias Sociales de la Universidad de Buenos Aires. Los planteamientos aquí esgrimidos fueron presentados como ponencia en el XII seminario ACIUR: La región como escenario de la reflexión territorial, realizado en Cali en septiembre de 2016.

${ }^{2}$ Doctora en Ciencias Sociales.
} 
political, economic and social factors that permeated that reality. The main conclusion reached is that the dictatorial centralism, established during the Quinquennium, subordinated Bogota's municipal administration to the interests of the central power. This situation led to a struggle for local autonomy that was used by the opposition to discredit the regime and promote the departure of Rafael Reyes into exile.

Keywords: Colombia; historiography; modernization; municipal administration; Rafael Reyes.

\section{Resumo}

O objetivo do artigo é reconsiderar o papel desempenhado pelo presidente Rafael Reyes (1904-1909) no processo de modernização urbana do Bogotá, à luz do que aconteceu nestes anos dentro da administração local. Metodologicamente, a análise será baseada num exame de fontes primárias e secundárias para entender o que aconteceu na cidade a partir de uma perspectiva multidimensional, correlacionando as mudanças experimentadas no planejamento urbano com os fatores políticos, econômicos e sociais que influenciaram essa realidade. A conclusão principal é que o centralismo ditatorial estabelecido durante o Quinquenio subordinou a administração municipal aos interesses do poder central. Esta situação levou nesse tempo a uma luta pela autonomia local, que foi usado pela oposição para desacreditar o regime e facilitar a saída de Rafael Reyes para o exílio.

Palavras-chave: Colômbia; historiografia; modernização; administração municipal; Rafael Reyes.

\section{Introducción}

La comprensión del pasado de las ciudades es un elemento indispensable para afrontar la realidad actual; por ello, toda investigación en historia urbana implica comprometerse a pensar la disciplina en función del "nexo pasado-presente-futuro" (Suárez, 2015a, p. 8). Optar por esta vía supone: a) evitar a toda costa la presunción de "que existe evidencia en el pasado de lo que el presente dicta" (Tenorio, 2012, p. 74); y b) contribuir activamente -en la medida de lo posible- a caracterizar los escenarios que a futuro puedan surgir, con miras a ayudar en la construcción de soluciones que permitan mejorar la vida en las urbes.

Inscritos en este marco, los historiadores urbanos tienen la responsabilidad de conocer a profundidad la historiografía existente alrededor de su tema de estudio, para de este modo identificar las preguntas, las tesis, que han marcado las disquisiciones sobre la materia, con el fin tanto de honrar a los precursores como de trascenderlos a través de la formulación de nuevas interpretaciones que estimulen el debate académico ${ }^{3}$.

Las páginas que siguen encuentran dentro de este horizonte su sentido: historiográficamente se ha tendido a sobrevalorar la actuación del presidente Rafael Reyes en el desarrollo urbano de Bogotá porque se ha interpretado su gestión sin ahondar en las particularidades del entorno municipal. La afirmación previa no pretende poner en entredicho la importancia del Quinquenio en el decurso histórico de la nación, sino investigar la realidad bogotana de los años que van de 1904 a 1909, centrando la

\footnotetext{
${ }^{3}$ El presente artículo se inscribe dentro de la historia urbana; esta disciplina "se ocupa de examinar la historia de un lugar urbano en el contexto de su amplio sistema económico, social, político, cultural y espacial", lo cual "inevitablemente localiza ese lugar en una red regional, nacional, internacional e inclusoive, transnacional" (Ewen, 2015, p. 12). La traducción del inglés es mía.
} 
atención en lo ocurrido en el seno de la administración local, en aras de reconsiderar algunos planteamientos sobre la capital colombiana que hasta ahora se han mantenido vigentes.

La convicción de la que se parte para abordar esta cuestión es que si se quiere comprender adecuadamente la historia urbana bogotana, es necesario cambiar la escala de análisis. Mirado el problema desde este ángulo es posible afirmar que la transformación más significativa acometida por el reyismo se dio en el plano administrativo: la centralización exacerbada que el General implementó en la capital fue precisamente la que incentivó que desde la oposición se reivindicara la autonomía local como una condición sine qua non para que el país progresara. La defensa del municipio como "base de la República" (Suárez, 2015a, p. 19) que se dio como respuesta a tal devenir no solo se convirtió en un elemento clave para desacreditar al régimen reyista, sino que además fue lo que permitió que a partir de la década de 1910 la ciudad iniciara su proceso de modernización urbana de la mano de la municipalidad (Suárez, 2006) ${ }^{4}$.

La hipótesis que al respecto se propone sugiere que la inquina con la que el General boyacense trató a los bogotanos debido al resentimiento que le generaba la élite capitalina, se tradujo en un centralismo dictatorial que se distinguió por subordinar la administración municipal a los intereses del poder central, situación que redundó en una agudización de las dificultades que venía presentando la ciudad desde finales del siglo XIX (Suárez, 2015a, p. 221) ${ }^{5}$.

En procura de examinar este planteamiento, la argumentación se fundamentará en un examen riguroso de fuentes primarias y secundarias que facultará para comprender lo ocurrido en la urbe desde una perspectiva multidimensional, es decir, correlacionando los cambios físicos experimentados en el damero con los factores políticos, económicos y sociales que permearon esa realidad.

Interesa recalcar que esta manera de aproximarse al problema implica admitir, como lo expresa Bernard Lepetit (2001), que la historia urbana actual no es una disciplina totalizante, sino que es una disciplina que reconoce que la ciudad permite múltiples miradas y enfoques porque es justamente en esa multiplicidad donde radica su esencia (Suárez, 2015a, p. 6).

Finalmente, antes de terminar esta introducción es preciso hacer una acotación sobre la estructura del artículo: en el primer apartado, se discurrirá sobre las bases historiográficas del problema; en el segundo, se explicará el concepto de ciudad insepulta acuñado por el historiador cartagenero Eduardo Lemaître para describir la Bogotá de comienzos del siglo XX. En el tercero, se examinará la realidad urbana de la capital colombiana durante el Quinquenio; y en el cuarto, por último, se efectuarán las conclusiones.

\footnotetext{
${ }^{4}$ Vale recalcar que el gobierno de Rafael Reyes se enmarca dentro del período conocido como la Regeneración. Historiográficamente existen diversas posturas sobre el espacio temporal que cubrió: Luis Javier Ortiz Mesa estima que se prolongó desde 1878 hasta 1902 (Ortiz, 2010, p. 250). Jorge Orlando Melo considera que abarcó desde 1885 hasta 1896 (Melo, 1989, p. 43). Eduardo Posada Carbó asevera que inició en 1880 y terminó en 1894 (Posada, 2015, p. 33 y 41); y Frédéric Martínez opina que inició en 1888 y acabó hacia 1900 (Martínez, 2001, p. 467). Lo que aquí se sostiene, de acuerdo con la investigación efectuada, es que comprendió los años que van de 1886 a 1910. Sobre esta cuestión remitirse a: Suárez (2015a) y Suárez (2017b).

${ }^{5}$ El bogotano es aquél que vive en Bogotá allende si nació o no en la urbe.
} 


\section{Los cimientos del problema: consideraciones historiográficas}

La labor de Rafael Reyes como dignatario ha sido exaltada en virtud, primordialmente, de su carácter ambicioso y emprendedor, típico del hombre de negocios que sobresalió por sus propios méritos gracias al trabajo constante, la disciplina y el esfuerzo. En la Nueva Historia de Colombia, Humberto Vélez lo define como "la pasión de la acción" pues, a su juicio, la "recia y aparente burda personalidad" del General "traducía la gran pasión del hombre moderno, inquieto, pragmático y superactivo en los negocios prácticos del mundo laborioso" (Vélez, 1989, p. 187).

La definición precedente no es producto del azar, sino parte integral de un discurso historiográfico que destaca las dotes del mandatario boyacense como "empresario y aventurero, político y militar" (Mesa, 1980, p. 96), con el único propósito de aseverar que su temperamento reunía todos los atributos requeridos para efectuar un cambio de rumbo en el territorio patrio.

Usando las palabras de Eduardo Lemaître, quien puede ser considerado el fundador de esta línea de interpretación:

la elección de Reyes como presidente de la república para el sexenio de 1904 a 1910 fue la reacción lógica de un país aniquilado por el abuso de la política y afanoso de ver hombres nuevos, con caras nuevas y sistemas nuevos al frente del gobierno; fue el resultado de un íntimo deseo de renovación que vivificaba al pueblo colombiano y que con certero instinto le indicaba en dónde estaba el hombre que podía, en esa hora, lograr la reconciliación de la destrozada familia colombiana (Lemaître, 1994, p. 225).

La condición de salvador que se le atribuye el General en la cita, al ser el único hombre capaz de lograr -en ese momento de la historia nacional- la reconciliación de la destrozada familia colombiana, paulatinamente generó que se acuñara la idea de que él era el prototipo del hombre moderno y del hombre burgués, entendiendo este último término en relación, tanto con su habilidad "para suscitar interés por las empresas de vuelo" (Ospina, 1987, p. 360), como con su afición por un gusto específico, ejemplificado en "las carreras, los juegos florales, las recepciones y los saraos" (Lemaître, 1994, p. 275). En el lenguaje de Humberto Vélez:

Rafael Reyes era un comerciante amante de las aventuras y riesgos económicos, circunstancialmente prestado a la política y a la actividad militar en las guerras civiles de 1885 y 1896; como típico hombre de negocios y de aventuras comerciales estaba siempre abierto al cambio y a las innovaciones en materia económica. Joaquín Tamayo, uno de sus mayores críticos desde el bando Liberal, lo presenta como un hombre abierto a las primeras manifestaciones mundanas de la modernidad, a quien fascinaban las carreras de caballos y las reuniones de negocios en los clubes sociales. Por otra parte, su ideología política funcionó casi siempre en función del

\footnotetext{
${ }^{6}$ La cursiva es mía. Téngase en cuenta que en 1966, Eduardo Lemaître afirmaba que su libro lo había escrito "hace ya casi veinte años" (Lemaître, 1994, p. 7). 
progreso económico, pues para el General boyacense la autoridad y el orden eran valores que no se justificaban por sí mismos sino que, por el contrario, constituían una de las condiciones políticas necesarias para impulsar el progreso económico (Vélez, 1986, p. 64) ${ }^{7}$.

La priorización de la primera vía, es decir, su destreza para los negocios, dio origen a una historiografía que le atribuyó a Rafael Reyes el mérito "de dar una visión más moderna del país", propiciando de esta forma "un cambio sumamente marcado en la atmósfera" (Ospina, 1987, p. 359-360) colombiana, debido -entre otras razones- a que su "política proteccionista le dio un impulso definitivo a la industrialización" (McGreevey, 1965$, p. 61$)^{8}$. El corolario de esto fue que se generalizó la concepción de que el gobierno reyista promovió "la modernización tanto económica como tecnológica" de la patria (Bushnell, 1996, p. 219), dando así lugar a "los comienzos del Estado moderno" (Mesa, 1980, p. 96).

La priorización de la segunda vía estimuló, en contrapartida, el surgimiento de una historiografía que introdujo el concepto de ciudad burguesa para describir la Bogotá de los años que van de 1820 a 1910. La obra que trazó este derrotero fue Los años del cambio. Historia urbana de Bogotá, 1820-1910, donde Germán Mejía Pavony estableció la analogía hombre moderno-ciudad moderna / hombre burgués-ciudad burguesa cuando afirmó que el concepto que usaba "de ciudad burguesa" correspondía "en sus características como en su cronología a lo que otros estudiosos" Ilamaban "ciudad moderna" (Mejía, 2000, p. 22) . $^{9}$

La tesis central de su escrito es que en el transcurso de dicho período la capital bogotana experimentó una transición que hizo posible que la urbe perdiera su aspecto colonial e ingresara al siglo XX, con "otro orden urbano, el burgués, acorde con las exigencias y necesidades de lo que para la época eran los nuevos tiempos" (Mejía, 2000, p. 480).

Si bien estos postulados han sido ampliamente debatidos en investigaciones anteriores (Suárez, 2017a; 2017b), para efectos del presente texto lo que interesa señalar es que en virtud de ellos se ha creado la imagen de que Rafael Reyes fue fundamental en el proceso de modernización urbana de Bogotá, sin que se hayan sopesado los matices de esta aserción. Hay que anotar que no se ignora la relevancia del Quinquenio como una etapa crucial en el decurso histórico del país, pero se busca comprender en toda su magnitud lo sucedido durante estos años.

Tal como lo ha manifestado Mauricio Archila al analizar el desarrollo económico que alcanzó Colombia bajo el reyismo, es indudable que "los incentivos" que el mandatario "otorgó a algunos empresarios permitieron el inicio de la industria textil, especialmente en la región antioqueña, así como de otras industrias de bienes de consumo" (Archila, 1991, p. 47). Sin embargo, "la ausencia de controles legales y de una prensa de oposición permitieron que estas acciones de fomento" y "otros asuntos similares

\footnotetext{
${ }^{7}$ La cursiva es mía.

${ }^{8}$ La traducción del inglés es mía.

${ }^{9}$ La analogía esbozada por Germán Mejía Pavony no gira en torno a Rafal Reyes sino a una serie de hombres modernos que cambiaron con sus negocios la fisonomía de la ciudad. El General boyacense es, en este sentido, un caso de muchos; no obstante, para la historiografía que prioriza la primera vía sobresale porque fue Presidente y desde esta posición estimuló el desarrollo capitalino.
} 
estuvieran acompañados de oscuros negociados que beneficiaron a los validos del régimen" (Melo, 1996, p. 59-60), situación que progresivamente generó que el General perdiera el apoyo político.

Indagar sobre la realidad bogotana desde esta óptica revisionista es, en suma, el objetivo de las páginas que siguen.

\section{La ciudad insepulta}

El 15 de agosto de 1953 Silvio Villegas publicó un artículo en Sábado en el que aseguraba que gracias a la labor de Rafael Reyes como "administrador insuperable de la cosa pública", "Bogotá se fue transformando en una metrópoli moderna" (Villegas, 1953, p. 8). La contundencia de su afirmación estaba sustentada -como él mismo lo explicaba- en la biografía del General que había escrito Eduardo Lemaître, obra que para entonces había "alcanzado ya los honores de la segunda edición" (Villegas, 1953, p. 3).

Vale aclarar que esa conversión de la urbe en una metrópoli moderna paradójicamente estaba ligada al "ambiente de corte europea" que el dignatario le había "comunicado" a la ciudad, circunstancia que en opinión del cartagenero era una de las causas por las cuales "el amanecer de la dictadura" había sido "saludado con beneplácito por la generalidad de los colombianos" (Lemaître, 1994, p. 275).

Lo relevante de esta cita es que hace evidente la permanencia en el tiempo de una concepción decimonónica de la capital que entendía a Bogotá como un mero reflejo del país; como se ha demostrado en otras investigaciones (Suárez, 2015b; Suárez, 2017a y Suárez, 2017b), a finales del siglo XIX los viajeros extranjeros que vivieron en suelo bogotano se encargaron de retratar la urbe como el pilar sobre el cual se erigió la patria $^{10}$. Martín García Mérou sintetiza esta premisa como sigue:

La historia de Colombia, está llena de nombres distinguidos en la ciencia, en las artes, en la política. Todos se han acogido al seno cariñoso de la capital, y aun en el día, los talentos más notables acuden a ella del confín de la República como creyendo indispensable su consagración (García, 1989, p. $117)^{11}$.

Tan hondo caló este postulado entre los connacionales que el sacerdote Federico Cornelio Aguilar llegó a asegurar en 1884 que la realidad denotada por Colombia era directamente proporcional al letargo en que se encontraba la urbe, pues esta era la única "Gran Capital" del continente que todavía conservaba "el aspecto, la suciedad, el

\footnotetext{
${ }^{10}$ Este postulado se sustenta en el análisis de los relatos de viaje de Charles Saffray (1984), Miguel Cané (1992), Martín García Mérou (1989), Ernest Röthlisberger (1993), Pierre d’Espagnat (1983), Eliseo Reclus (1893), William L. Scruggs (1900), Francis Loraine Petre (1906) y Hiram Bingham (1909). No se abordará en detalle este tópico porque no es objeto del presente texto, pero se recomienda remitirse a la bibliografía citada para profundizar en la materia. Cabe recalcar que una obra pionera en la utilización de dichos relatos como fuente primordial para comprender la historia bogotana es el libro de Carlos Martínez (1978) titulado Bogotá reseñada por cronistas y viajeros ilustres (1572-1948).

${ }^{11}$ La cursiva es mía.
} 
atraso, el estancamiento y las preocupaciones raizales de la Colonia"12. La única, además, que aún carecía de "las comodidades, inventos y adelantos de las ciudades modernas" pese a ser una de las más "grandes, populosas e importantes de la América española" (Aguilar, 1884, p. 69-70) ${ }^{13}$.

Es pertinente indicar que la expresión más acabada de esa equiparación de la capital con el país, antes mencionada, fue el surgimiento del término Atenas Suramericana para referirse a Bogotá, calificativo que fue utilizado después de la segunda mitad del siglo XIX para otorgarle a la ciudad la responsabilidad de ser "la orientadora espiritual y mentora de Colombia" (Ortega, 1990, p. 415).

Los fundamentos de lo que en otro texto se ha denominado "el mito" de la urbe ateniense" (Suárez, 2008) fueron la "sabiduría", la "afabilidad y cultura" (Gómez, 1938, p. 90) mostrada por los bogotanos, atributos que fueron, al mismo tiempo, exaltados y criticados por los connacionales y extranjeros de las postrimerías de la centuria decimonónica $^{14}$.

Un ejemplo de esa manera dual de aceptar dicho apelativo, en el contexto de la analogía señalada, son las palabras de Pierre d'Espagnat (1983) que se enuncian a continuación:

Audacia peligrosa para un pueblo joven y pequeño es la de aceptar, descartada la posibilidad de que en ello haya la menor malicia, la herencia moral más cargada de gloria, el mote más soberbio y más difícil de ostentar, el de sucesor de la armonía de la divina Atenas. ¿Cabría considerarlo como una burla gratuita al comprobar la ausencia de la Acrópolis, de sus Propileos y del Pnix? Pero todavía sería más injusto desconocer o no apreciar en su justo valor la sinceridad y el alto vuelo de las preocupaciones intelectuales, literarias, y sobre todo, científicas de la sociedad bogotana (d'Espagnat, 1983, p. 79$)^{15}$.

Un punto a subrayar, dentro de este ámbito, es que la aparente contradicción entre la capital descrita por Federico Cornelio Aguilar y la capital que dio origen a la idea de la Atenas Suramericana, no es tal; por el contrario, es parte integral de la dicotomía interior-exterior que mostró Bogotá a finales del siglo XIX, claramente evidenciada en los relatos de Miguel Cané (1992) y Martín García Mérou (1989). Tal como se ha demostrado en una investigación previa, la exaltación que ambos diplomáticos

\footnotetext{
${ }^{12}$ La capitalidad de Bogotá fue frecuentemente referenciada en la segunda mitad del siglo XIX por los colombianos, como se evidencia en "Las tres tazas" de José María Vergara y Vergara (Vergara, 1936) y en las "Memorias" de Salvador Camacho Roldán (Camacho, 1946). Al respecto este último dice: "No era Bogotá, como es hoy, el centro principal de cultura de nuestro país" (Camacho, 1946, p. 127).

${ }^{13}$ Aquí se enfatiza en la obra de Federico Cornelio Aguilar por dos motivos: a) porque compendia a la perfección las críticas que se harán a la urbe a fines del siglo XIX; y b) porque se siguió citando en la prensa capitalina hasta comienzos del XX. Sobre este punto, véase: Suárez, 2015a. Federico Cornelio Aguilar fue un sacerdote jesuita, de origen antioqueño, que desde 1874 se puso como objetivo publicar "un libro de viajes que vendría a aumentar la literatura nacional" (Suárez, 2015a, p. 344).

${ }^{14}$ Este tema ya ha sido analizado a profundidad en otra investigación, así que se recomienda remitirse a la bibliografía para ampliar la información; al respecto, véase: Suárez (2008) y Suárez (2017a). Las palabras citadas por Antonio Gómez Restrepo corresponden "al señor Lisboa, Ministro del Brasil, quien arribó al país en 1852" (Gómez, 1938, p. 90).

${ }^{15}$ La cursiva es mía. Pierre d'Espagnat fue un viajero francés que llegó al país a mediados de 1897.
} 
argentinos hicieron de la cultura e ilustración de los bogotanos se erigió de esta forma en el contrapeso perfecto para atenuar la impresión que les causó la miseria e insalubridad que denotaba su entramado urbano (Suárez, 2015a, p. 85).

Enfatizar en esta cuestión es indispensable para entender de qué forma historiográficamente se ha exaltado la gestión de Rafael Reyes en el desarrollo citadino. Los raciocinios esgrimidos al respecto utilizan la ciudad como el campo de batalla en el que el dignatario debió sortear los obstáculos de los "innumerables versificadores" que se encontraban en el poder, concentrado en Bogotá (Lemaître, 1994, p. 220).

Fundándose en la lógica de la correlación capital-país, Eduardo Lemaître difundió la idea de que no había mayor aspiración para un joven colombiano "que hacerse literato, ganar fama como poeta, y entrar luego, por la puerta dorada de las letras, al maravilloso mundo de la política" (Lemaître, 1994, p. 220), cuyo centro de acción era la capital bogotana.

La imagen de la nación que él creó alrededor de este postulado se afincó en la premisa de que Colombia era una República de intelectuales y Bogotá "una ciudad insepulta" (Lemaître, 1994, p. 219). Según lo expresaba el cartagenero, en una patria donde la juventud se dedicaba exclusivamente a la política o a sus "alternativas" -a saber, desempeñarse como "picapleitos, agricultores en pequeño o pedagogos dedicados a educar a la generación que venía detrás de ellos envenenándola conforme a sus respectivos odios partidistas"(Lemaître, 1994, p. 220)-, su capital no podía tener un destino diferente que el del permanente atraso (Lemaître, 1994, p. 220).

La versión de la historia que acuñó sobre esta base dio a entender que el territorio patrio se había transformado con la llegada de Rafael Reyes a la presidencia, pues al momento de empezar la contienda electoral que le había dado al General boyacense la victoria:

Todo estaba por hacer en Colombia, en cuanto a su progreso material y a su restauración moral. Por lo que a las ciudades y pueblos del país respecta, el espectáculo que a los ojos de cualquier visitante se ofrecía era bien triste. Las que, flamantemente se llamaban capitales de departamentos, no eran, por cierto, al comenzar [el siglo XX] sino miserables villorrios sin vigor social y sin espíritu público ninguno. (...) Y la misma capital de la República era un poblacho sucio y carente de acueducto, de luz eléctrica y de alcantarillado, cuyo monótono ambiente era apenas turbado, de tarde en tarde, por un tranvía de mulas que escandalizaba con el tintineo de sus cascabeles el silencio de la neurasténica ciudad. Allí era todo triste y ruinoso. (...) Aquella capital colombiana no tenía, pues, de tal, sino el nombre, y no es de extrañar que, comentando la fetidez de algunas de sus calles, por cuyo centro cruzaba el arroyo descubierto de las alcantarillas, el escritor cubano Emilio Bobadilla (Fray Candil) hubiera lanzado aquella caústica frase (...): “iBogotá es una ciudad insepulta!" (Lemaître, 1994, p. 218-219) ${ }^{16}$.

\footnotetext{
${ }^{16}$ La cursiva es mía; se utiliza para enfatizar la idea proporcionada en la cita. Las palabras entre corchetes ([]) no pertenecen al texto original sino que se introducen para mantener la coherencia gramatical; este mismo procedimiento se utilizará a lo largo del escrito.
} 
La descripción de la capital presentada por el historiador cartagenero no solo no se condice con la realidad histórica de la época en la medida en que revela un desconocimiento de la lucha que en la década de 1890 llevó a cabo la administración local para hacer respetar los derechos del municipio a favor del público capitalino, sino que además se encarga de reproducir la antipatía que Rafael Reyes sentía por los bogotanos ${ }^{17}$.

Interesa anotar que este sentimiento era compartido -como lo comentaba el propio General- por Rafael Núñez, quien al conocerlo en 1883 le había expresado que "sabía que su vida corría peligro, porque ya se le había amenazado por los clubs de demagogos de la capital" (Reyes, 1986, p. 284) ${ }^{18}$. La recurrencia, en efecto, con la que el General profería en sus escritos comentarios negativos sobre "la alta clase social" pone de manifiesto que, en su pensamiento, Bogotá simbolizaba el núcleo de "la injusticia y el exclusivismo" (Reyes, 1986, p. 249-250).

Las palabras que le dedicó en sus Memorias a la ciudad corroboran esta apreciación; según lo exponía, la localización de la urbe donde "transcurría la vida política" nacional, "ubicada a mil kilómetros de la costa", hacía que "el progreso allí fuera más lento y que la actividad se empleara en debates" partidistas "que se extendían a las ciudades departamentales y que mantenían al país en constante alarma", pues apenas terminaba "una insurrección ya se estaba preparando o fomentando otra" (Reyes, 1986, p. 249).

Igualmente, haciendo eco de un informe elaborado por un visitador real que había vivido en Bogotá y que, "según decían", reposaba "en el Archivo de Indias en Simancas", Rafael Reyes afirmaba que sus habitantes eran "cultos y hospitalarios", pero que "las enemistades, rencillas, envidias, etc." entre ellos "eran tan intensas" que hacían que la vida en su suelo fuera "insoportable" (Reyes, 1986, p. 250-251).

La animadversión que se percibe en su relato es un factor a considerar para comprender las disposiciones que el dignatario adoptó con respecto a la capital. Una de las más relevantes fue la promulgación de la Ley 17 de 11 de abril de 1905 que erigió al municipio de Bogotá en Distrito Capital, ya que en virtud de esta el poder central quedó autorizado a reglamentar -a través "de decretos ejecutivos"- todo lo relativo a "rentas, contribuciones, policía, alumbrado, servicio de aguas, locomoción, aseo y ornato, y en general", a lo que correspondiera a la ciudad para "construir los parques, paseos públicos, y demás obras de interés” (La Fusión, 1905, s.p.).

La concreción de dicha directriz supuso imponer en el ámbito capitalino un centralismo incluso más férreo que el practicado por los gobiernos previos, ya que le quitó a la "corporación" (República de Colombia, 1911, p. 59) municipal las atribuciones asignadas en la Constitución de 1886. La aplicación de la norma hizo preciso que el Ejecutivo expidiera el Decreto 509 de 25 de mayo de 1905 por medio del cual "la antigua Municipalidad fue reemplazada por un Consejo Administrativo compuesto de cinco miembros principales y otros tantos suplentes" elegidos anualmente por el mandatario, el cual se instaló en la urbe el 16 de junio de 1905 bajo la presidencia del Gobernador del Distrito Capital, Jorge Vélez (Vélez, 1906, p. 3-4).

\footnotetext{
${ }^{17}$ La palabra en cursiva es propia de la época; a finales de siglo XIX la noción de lo público se utilizaba tanto para referirse al pueblo como para aludir al bien público. Véase: Suárez (2017a).

${ }^{18}$ Las memorias de Rafael Reyes fueron compiladas por su nieto, Ernesto Reyes Nieto, quien "durante 11 años guardó los cuadernos" que contenían tales testimonios (Reyes, 1986, p. 10).
} 
La fusión de la administración municipal con el poder central perpetrada por el reyismo convirtió de este modo la analogía decimonónica de la capital con el país en una verdadera amalgamación (Suárez, 2015a, p. 229) ${ }^{19}$.

\section{La Bogotá reyista}

Tras la creación del Distrito Capital, el 24 de mayo de 1905 el periódico El Reporter identificó cuáles eran las necesidades más urgentes de Bogotá; a saber: a) la "canalización de los ríos San Francisco y San Agustín"; b) la creación de un "Tribunal de Sanidad Pública"; c) la formación del "alumbrado eléctrico"; d) el establecimiento de "excusados públicos"; e) la edificación "de una casa de asilo, de corrección y de enseñanza para los centenares de muchachos vagos" que proliferaban en la urbe; f) el "arreglo del pavimento de las calles más centrales"; g) la organización "de un correo urbano"; y h) el "traslado del Hospital" a otra zona de la grilla (El Reporter, 1905a, s.p.).

La sincera preocupación que mostró el diario por el desarrollo de la urbe se vio complementada, pocos días después, con la publicación de un artículo donde se elogiaba la decisión del burgomaestre, Julio D. Portocarrero, de expedir el Decreto 24 de 23 de mayo de 1905 por medio del cual quedaba prohibida la mendicidad en Bogotá. A partir del 2 de junio siguiente, la policía tenía el deber de recoger y conducir al "Asilo, situado en Tres esquinas, a todo individuo que se hallare pidiendo limosna en las calles, plazas y casas", normatividad que según el periodista era digna de "aplausos" porque, a su juicio, "nada hacía más desagradable" a la ciudad "que esa multitud de cojos, ciegos, tullidos que se paseaban haraposos y malolientes" por el damero (El Reporter, 1905b, s.p.).

El beneplácito con el que se acogió el accionar del burgomaestre pronto se vio truncado debido a la nueva reforma administrativa efectuada por el General. Tanto el anuncio (consignado en el Decreto 509 de 1905) de que en adelante el Distrito Capital sería regido por "un Gobernador de libre nombramiento y remoción por parte del Presidente" (Reyes, 1905, s.p.), como la determinación de crear "ocho Alcaldías para los barrios de la ciudad" (Vélez, 1906, p. 4), propiciaron que durante los meses siguientes la prensa local se dedicara a denunciar el deplorable estado en el que se hallaba la urbe.

Una nota divulgada el 16 de junio de 1905 en el periódico Bogotá aseveraba que el "Decreto de mendigos no se había cumplido de manera absoluta", pues todavía había muchos deambulando por las calles a quienes "la policía no prendía porque llevaban vestido nuevo para despistar" (Bogotá, 1905a, s.p.) ${ }^{20}$.

La queja precedente, lejos de ser un hecho aislado, era testimonio del descontento generalizado que comenzó a sentirse entre la población, al percatarse de que las providencias adoptadas por el General boyacense lo único que habían logrado era

\footnotetext{
${ }^{19}$ Un decreto especial, posteriormente expedido por el Ejecutivo Municipal, determinó que el Distrito Capital quedaría conformado por Bogotá y por los doce municipios (Bosa, Cota, Chía, Engativá, Funza, Fontibón, La Calera, Mosquera, Soacha, Suba, Usaquén y Usme) que antiguamente conformaban la Provincia de Bogotá (Vélez, 1906, p. 4).

${ }^{20}$ Las críticas elevadas por el periódico Bogotá ocasionaron que el Gobierno decretara la suspensión del diario.
} 
reiterar y agudizar los males de antaño. Un tema que se volvió recurrente en los periódicos fue la permisividad con la que las autoridades consentían que se arrendaran "para habitación ciertos locales que, por carecer de water-closet" daban lugar para que, quienes vivían en ellos, "arrojaran a la calle líquidos bastante impropios para perfumar" (Bogotá, 1905b, s.p.).

Los señalamientos de la prensa abarcaban una amplia variedad de tópicos: si bien las alusiones a los focos de infección que existían en la capital, al polvo que imperaba en las calles, a la ausencia de retretes y de baños públicos y al hacinamiento de personas registrado en diferentes puntos del centro urbano, tenían como elemento común la carencia de agua que experimentaba el entramado capitalino desde finales del siglo $\mathrm{XIX}$, lo cierto es que paulatinamente fueron surgiendo otros reproches que certifican la apatía con la que el poder central trataba a la capital ${ }^{21}$.

El periódico El Escudo, dando indicios sobre este derrotero, escribió a comienzos de septiembre de 1905 lo que sigue:

Mucho se ha preocupado la actual administración del mejoramiento de nuevas vías de comunicación; basta decir que las carreteras de Cundinamarca se han mejorado de una manera notable, pero en [plena Bogotá], en uno de nuestros paseos más concurridos, en el Camellón de la alameda que conduce a uno de nuestros mejores parques [(el del Centenario)], y por donde transita gran número de pasajeros, o sea en la carrera 13, entre las calles 24 y 25 , se encuentra un caño o alcantarilla descubierto, y en tal estado de infección que es imposible pasar por allí. Nos permitimos llamar respetuosamente la atención del Ministro [del ramo], del Sr. Prefecto del Distrito y de las autoridades, para que tomen el respectivo interés, [para] que [el] caño se cubra [y] evitar las emanaciones malsanas que causan tantos males (El Escudo, 1905, s.p.).

Hay que destacar que estas críticas fueron efectuadas más de seis meses después de la promulgación del Decreto Legislativo 34 de 10 de febrero de 1905 por medio del cual el Ejecutivo quedó autorizado para construir edificios y establecimientos destinados a fomentar el embellecimiento y la salubridad de Bogotá.

Indiscutiblemente, en esta norma se contemplaban cambios significativos para la infraestructura local, pero no se puede olvidar que: a) algunas de las cláusulas allí consignadas respondían a iniciativas planeadas con anterioridad, tal como sucedió con el Capitolio, obra que desde el mandato de José Manuel Marroquín (1900-1904) había sido calificada como prioritaria para la patria (Suárez, 2015a, p. 235-236; y 2015b) varios de los proyectos planeados no se materializaron, o si lo hicieron, sus resultados fueron más "modestos" de lo que frecuentemente se ha afirmado (Corradine, 2002, p. 188).

Un ejemplo palmario de lo anterior es el relato que hace Alberto Corradine Angulo en relación con el edificio de Las Galerías, cuya obra:

${ }^{21}$ Bogotá aseveraba al respecto: "en la calle $9^{a}$ en la cuadra de la Imprenta Nacional, hay unas tiendas pequeñísimas en donde se da asistencia y que impregnan toda la cuadra de un olor nauseabundo de cocina" (Bogotá, 1905c, s.p.). 
[debió] ejecutarse en el transcurso de varios años, y en etapas diferentes y no en uno solo como pretende indicar Herrera Pérez en su estudio. (...)

El lento avance de las obras puede comprenderse mejor teniendo en cuenta las propias expectativas de la comunidad, traducidas en comentarios de prensa, no siempre positivos. Es así como al promediar el año de 1909 se [hablaba] de: "En el edificio de las Galerías queda todavía un boquete que bien se podría tapar con mucha facilidad, con un impuesto sobre ruinas, el dueño no se haría esperar tanto". (...)

Por otra parte, las inversiones tardías que [hizo] el Municipio en los años de 1909 y 1910, se [refieren] precisamente al remate del pabellón sur (Corradine, 2002, p. 192).

Huelga decir que las cifras estipuladas en el presupuesto de gastos hacen suponer que las condiciones de la ciudad debieron cambiar sensiblemente para 1906, si se tiene en cuenta que la asignación para el Departamento de Obras Públicas (sin contar los sueldos de los empleados) fue de $\$ 231.910$ pesos oro, mientras que la correspondiente al Departamento de Salubridad y Beneficencia fue de $\$ 68.320$ pesos oro (Vélez, 1906, p. 29). No obstante, al examinar en detalle el informe elaborado por el Gobernador del Distrito Capital se constata que dichos montos fueron adjudicados en función de los $\$ 254.000$ pesos oro que debían ingresar al erario por concepto de la recaudación del impuesto predial, cuantía que en realidad "apenas alcanzó a llegar a la mitad" debido a que en el transcurso de ese período el "Gobierno nacional decidió rebajar la tasa de dicho gravamen" (Vélez, 1906, p. 27).

Otra cuestión que sin duda afectó el desarrollo de las obras que debían ponerse en marcha en Bogotá fueron las acusaciones de corrupción que empezaron a propagarse a partir del primer año de gestión de Rafael Reyes. La carestía de los alimentos básicos, las quiebras de los bancos o la falta de crédito fueron factores que incidieron en la cotidianidad de la capital. El retrato realizado por Hiram Bingham en 1907 de la urbe enfatizaba, dentro de este marco, en el hecho de que el espacio capitalino continuaba exteriorizando una imagen que daba cuenta de la pervivencia en el tiempo de unos signos decimonónicos. Las aceras repletas de mendigos, los tumultos formados en el Altozano, la escasa circulación de monedas de oro y plata, las deficiencias en el servicio de alumbrado, la pobreza que se percibía en los barrios y los olores nauseabundos eran claro reflejo de ese acontecer (Suárez, 2015a, p. 237).

Un elemento a recalcar es que la narración del norteamericano igualmente exteriorizaba hasta dónde las labores realizadas en la trama citadina estaban vinculadas a la exaltación personal del dignatario; según lo comentaba, la inauguración del Parque de los Hermanos Reyes en el Bosque de San Diego, a la cual asistió, obedeció al interés del General de evocar la memoria de Néstor y Enrique, quienes habían perecido en una expedición por las selvas inhóspitas del sur del país (Bingham, 1909, p. 245).

Tan patente fue esta situación para los capitalinos que, ad portas de la celebración del Centenario, la prensa bogotana manifestó su inconformidad porque una celebración de tanta magnitud se llevara a cabo en un escenario que rememoraba prácticas dictatoriales, polémica que a la postre originó que el sitio fuera rebautizado con el nombre de Parque de la Independencia (Suárez, 2015a, p. 238). 
Lo acaecido en el ámbito capitalino durante 1908 ratifica la imposibilidad de calificar a Rafael Reyes como el modernizador de Bogotá. El informe presentado por el Ingeniero del Distrito Capital revela que los adelantos emprendidos en la urbe se circunscribieron, esencialmente, a la adecuación de pavimentos, empedrados o adoquinados; al levantamiento de algunos puentes y murallas; a ultimar obras ya emprendidas y a refaccionar las que seguían en pie (República de Colombia, 1908a, p. 464-469). No en vano, en el libro titulado Arquitectura de Bogotá, Alfredo Ortega destaca la importancia de la pavimentación, pero matiza la magnitud de lo que se hizo al aseverar: "La obra de pavimentación moderna, iniciada durante el gobierno del señor Álvaro Uribe, como Gobernador del Distrito Capital, en 1908, comenzó con el asfaltado de una carrera y el enladrillado de una calle, de las de mayor tráfico" (Ortega, 1924, p. 88).

La tabla 1, que se presenta a continuación, es una muestra de lo que se está señalando pues, al contrastar el número de los puentes construidos (uno de ellos justamente en las inmediaciones del Parque de los Hermanos Reyes) con el número de puentes reparados, se puede evidenciar que la cifra correspondiente al segundo caso (trece en total), casi triplica la concerniente al primero (cinco en total).

\section{Tabla 1. Obras realizadas en el Distrito Capital. 1908.}

\begin{tabular}{|c|c|}
\hline Puentes construidos & Puentes reparados \\
\hline $\begin{array}{l}\text { Puente de Boyacá, sobre el río San Francisco, entre las } \\
\text { cuadras } 1^{\mathrm{a}} \text { y } 2^{\mathrm{a}} \text { de la calle } 19 \\
\text { Uno en el Paseo Bolívar, al oriente del Parque de los } \\
\text { Hermanos Reyes } \\
\text { Uno sobre la quebrada de San Juanito, entre las cuadras } 1^{\mathrm{a}} \\
\text { y } 2^{\mathrm{a}} \text { de la carrera } 4^{\mathrm{a}} \\
\text { Uno en la carrera } 6^{\mathrm{a}} \text {, sobre la quebrada de La Cabrera } \\
\text { Uno sobre el río Fucha, en el sitio de San Vicente }\end{array}$ & $\begin{array}{l}\text { Los Mártires } \\
\text { Cundinamarca } \\
\text { El Telégrafo } \\
\text { La Lira } \\
\text { Bolívar } \\
\text { San Agustín (en la } \\
\text { carrera 7aa) } \\
\text { Holguín } \\
\text { Gutiérrez } \\
\text { Núñez } \\
\text { Caldas } \\
\text { Arrubla } \\
\text { Lesmes } \\
\text { Colón }\end{array}$ \\
\hline
\end{tabular}

Fuente: Tabla realizada con base en la información proporcionada en República de Colombia (1908a, p. 468). Téngase en cuenta que los puentes fueron construidos en ladrillo y piedra, con excepción del que se erigió sobre el río Fucha que era de "dos ojos y tablero de madera" (República de Colombia, 1908a, p. 468).

Haciendo eco de lo que planteó Carlos Niño Murcia para este período en Arquitectura y Estado. Contexto y significado de las construcciones del Ministerio de Obras Públicas. Colombia, 1905-1960, se puede afirmar que las obras emprendidas en el período 1904- 
1909 en realidad se enfocaron primordialmente en la realización de "reparaciones urgentes", en vez de en la búsqueda de una solución definitiva a los problemas que desde finales del diecinueve venía presentando la urbe (Niño, 1991, p. 41).

Vale anotar, sin embargo, que la transformación más relevante de este período ocurrió en el plano administrativo: con la sanción de la Ley $1^{\circ}$ del 5 de agosto de 1908, planeada para regir a partir del $1^{\circ}$ de enero de 1909, el Gobierno amplió el número de departamentos, centralizó las rentas y contribuciones de los que fueron suprimidos y dejó la puerta abierta para que el presidente pudiera restablecer, cuando lo creyera oportuno, el Cabildo bogotano (República de Colombia, 1908b, p. 15-22).

Unos días después, por medio del Acto Legislativo 2 de 12 de agosto de 1908, se le restituyó a los Consejos Municipales la responsabilidad de ordenar lo conveniente, a través de acuerdos o reglamentos interiores, para la administración local (República de Colombia, 1908a, p. 41).

El ministro de Gobierno, Marceliano Vargas, justificó dicha norma arguyendo que su aplicación iba a contribuir para "que las ciudades capitales, merecedoras de especial consideración por su importancia histórica y por el papel que estaban llamadas a desempeñar, disfrutaran de todos los beneficios de la civilización moderna", estimulándolas para que fueran "factores valiosos en la prosperidad" de la nación (República de Colombia, 1908a, p. 6).

Las fuentes demuestran que los cambios implementados no dieron los resultados esperados por el régimen. La "discusión del tratado firmado en 1909 por el liberal Enrique Cortés y el Secretario de Estado de los Estados Unidos, Elihu Root”, para "normalizar las relaciones" con este país y poner "punto final al conflicto sobre Panamá" (Melo, 1996, p. 60), aunada a las constantes denuncias sobre estafas, contratos arreglados y favoritismos que rodeaban al Gobierno, propiciaron que el 13 de marzo de 1909 se diera en Bogotá una manifestación estudiantil en contra del Ejecutivo que terminó desencadenando la renuncia del General, el nombramiento del Designado, Jorge Holguín, para reemplazarlo en el cargo y la declaración, por medio del Decreto 286 de 1909, del "estado de sitio en la ciudad" (El Nuevo Tiempo, 1909a, s.p.) ${ }^{22}$.

La implementación de esta última disposición significó incorporar a "la Policía nacional en el Ejército"; prohibir los grupos de más de cinco personas en el damero citadino; permitir el tránsito por las calles bogotanas después de las siete de la noche únicamente a quienes tuvieran una boleta especial de la Comandancia de la Gendarmería; y ordenar que en todas las Alcaldías se abriera un libro de registro en el que los ciudadanos defensores del orden tenían la obligación de inscribirse, so pena de que el Ministerio de Guerra los investigara para averiguar si eran cómplices o simpatizantes de los manifestantes (El Nuevo Tiempo, 1909b, s.p.).

La negativa de la Asamblea Nacional para aceptar la renuncia del dignatario ocasionó que Rafael Reyes regresara el 14 de marzo de 1909 al poder. Las dos medidas más relevantes que adoptó tras retornar a la presidencia fueron: a) convocar a comicios para elegir al "primer Congreso de elección popular" que habría de instalarse el 20 de julio siguiente (Reyes, 1909a, s.p.); y b) expedir la Ley 8 de 7 de abril de 1909 en la que

\footnotetext{
22 David Bushnell, siguiendo el discurso de Eduardo Lemaître, sostiene lo siguiente: "Los manipuladores de la opinión pública, los intelectuales y en general las personas que se oponían a Reyes en cualquier aspecto" suscitaron "un fuerte sentimiento antirreyista, como se reflejó en los serios desórdenes públicos que tuvieron lugar en Bogotá en marzo de 1909" (Bushnell, 1996, p. 222).
} 
derogaba su decisión de concentrar las rentas en manos del Estado (Camacho, 1909, s.p.). En conformidad con esta última disposición, el régimen le devolvió a las secciones el control de los impuestos que habían perdido en la postrera división territorial y les concedió, adicionalmente, las contribuciones concernientes a Licores nacionales, Degüello de Ganado Mayor, Registro y Anotación. El General asimismo anunció que procedería a reinstalar en sus funciones a la Municipalidad bogotana, entidad que debió esperar hasta noviembre de 1909 para recuperar su carácter popular.

El clima de tensión que para entonces imperaba en el país provocó que el General resolviera el 4 de julio de 1909 abandonar la capital con el pretexto de emprender una gira por el territorio patrio orientada tanto a inspeccionar las obras de infraestructura como a estrechar las relaciones con las autoridades municipales. Tras cuatro días de travesía, Rafael Reyes proclamó un Manifiesto donde explicaba que le había conferido temporalmente el Poder Ejecutivo a Jorge Holguín con miras a que quedara la tranquilidad de que "la buena marcha" de la nación no estaba ligada ni a su gestión ni a sus influencias (Reyes, 1909b, s.p.).

La salida del General al exilio, acaecida poco después de proferir estas palabras, puso al descubierto los numerosos desfalcos cometidos durante su mandato por la administración local. Uno de los casos más graves involucró al Administrador del Cementerio y a su segundo, quienes fueron acusados de un sinnúmero de fechorías que abarcaban desde la malversación de los bienes del Distrito hasta la desaparición de cadáveres (Suárez, 2015a, p. 248).

Aunque la investigación realizada por El Nuevo Tiempo desató un sonado escándalo, este incidente fue uno más dentro de las diversas denuncias proferidas en esos años en torno -entre otras cuestiones- al pésimo servicio telefónico, al contrato celebrado con la Empresa de Tranvías, a la monopolización del suministro de agua por parte de la Compañía del Acueducto, y a la "inútil" oficina creada por la Gobernación "para leer los avisos y carteles que se fijaban en las esquinas" (El Nuevo Tiempo, 1909c, s.p.). La Bogotá que finalizaba el Quinquenio presentaba de esta forma un balance desalentador.

\section{Conclusiones}

La investigación precedente pone en perspectiva la importancia de Rafael Reyes en el proceso de modernización urbana de Bogotá. Más que por las obras realizadas, el régimen fue fundamental para incentivar un cambio dentro de la administración local que hizo posible dos cosas: la primera, que a partir de la década de 1910 la urbe experimentara un notable desarrollo espacial (Suárez, 2006); y la segunda, que la autonomía municipal se erigiera en una condición indispensable para que el país pudiera progresar.

Inscrita en este marco, la reflexión final de este escrito sugiere que la postura apologética con la que frecuentemente se ha interpretado el Quinquenio ha reforzado la inquina de las regiones hacia la capital y, al mismo tiempo, ha impedido analizar en su justa dimensión el régimen reyista. La obra de Eduardo Lemaître ha sido crucial en este decurso justamente por la huella que ha dejado en la historiografía nacional; según este historiador, si Rafael Reyes hubiera gobernado en "un país de más avanzada 
civilización política" quizás "no solamente habría sido buen administrador de la cosa pública, sino un gobernante ejemplar en cuanto al estricto cumplimiento de las normas y reglamentaciones constitucionales". No obstante, "los tiempos eran malos y una serie de acontecimientos concatenados iban a conducir al nuevo mandatario hacia el único camino que, en épocas de tormenta, suelen tomar todas las repúblicas: la dictadura" (Lemaître, 1994, p. 247).

La explicación por él dada para justificar que el General hubiera tenido que convertirse en dictador, o la alusión a la "dictadura moderada" de la cual habla Bushnell, son pruebas irrefutables de la lectura tendenciosa con la que hemos reconstruido algunos períodos de nuestra historia, situación que a la postre ha generado la consolidación de un discurso histórico que polariza al país.

Testimonio de lo anterior es la máxima menos política y más administración que Rafael Reyes adoptó como eje de su programa de gobierno, pues historiográficamente ha sido utilizada para ilustrar la distancia que había entre el pensamiento progresista del dignatario y la mirada estrecha de los "intelectuales" bogotanos (Lemaître, 1994, p. 245). En la terminología de Humberto Vélez:

[Con Reyes] el país tenía, pues, a su cabeza, tal vez no a un hombre de estado, pero sí a un administrador competente, a una especie de gerente de una gran empresa. Un gobernante así se salía de los moldes clásicos de los presidentes colombianos: formalistas, gramáticos, teólogo, metafísicos, especulativos. Para el grupo más numeroso de la intelectualidad de principios del siglo $X X$, el presidente era un personaje raro, que en vez de pensar en la guerra o en ponerse a escribir entre poema y poema sus memorias, se mantenía hablando de política monetaria, de proteccionismo industrial y de estímulos estatales; y esa misma intelectualidad, formalista y versificadora, no salía de su asombro cuando el presidente sustituyó el viejo y gastado discurso de poetas y filólogos por una ideología pragmática, que veía en el orden y la autoridad una condición para poder adelantar obras de progreso económico, y no unos valores que se justificasen por sí mismos, como era la visión más tradicional (Vélez, 1989, p. 188) ${ }^{23}$.

Lo cierto es que esta dualidad ha sido la base de una división irreconciliable que todavía se mantiene vigente en el país entre las regiones, personificadas en el "hombre enérgico y el empresario audaz" que era el general boyacense; y Bogotá, representada en "los hombres de pluma, los eruditos de biblioteca, los gramáticos, los pedagogos, los retóricos y los profesionales de la política" que componían la élite capitalina (Lemaître, 1994 p. 245).

Insistir en esta última idea, repitiendo unos planteamientos que no se condicen con la realidad bogotana del Quinquenio es, en conclusión, continuar estimulando que el pasado así interpretado determine equívocamente el presente y el futuro de la nación.

\section{Referencias}

${ }^{23}$ La cursiva es mía. 
Aguilar, F. C. (1884). Colombia en presencia de las Repúblicas Hispano-americanas por el presbítero Dr. Federico C. Aguilar. Residente en ellas durante veinte y seis años. Bogotá, Colombia: Imprenta de Ignacio Borda.

Archila, M. (1991). Cultura e identidad obrera. Colombia 1910-1945. Bogotá, Colombia: CINEP.

Bingham, H. (1909). The Journal of an Expedition across Venezuela and Colombia, 1906-1907. United States / London, UK: Yale Publishing Association / T. Fisher Unwin.

Bogotá. (16 de junio de 1905a). No han cumplido. Bogotá, s.p.

Bogotá. (16 de junio de 1905b). La Policía. Bogotá, s.p.

Bogotá. (4 de agosto de 1905c). Higiene. Bogotá, s.p.

Bushnell, D. (1996). Colombia: una nación a pesar de sí misma. De los tiempos precolombinos a nuestros días. Bogotá, Colombia: Editorial Planeta.

Camacho, N. (27 de marzo de 1909). Importante Proyecto de Ley. El Nuevo Tiempo, s.p.

Camacho, S. (1946). Memorias. Bogotá, Colombia: Editorial A.B.C.

Cané, M. (1992). Notas de viaje sobre Venezuela y Colombia. Bogotá, Colombia: Tercer Mundo Editores.

Corradine, A. (2002). Apuntes sobre Bogotá. Historia y Arquitectura. Bogotá, Colombia: Academia Colombiana de Historia.

d'Espagnat, P. (1983). Recuerdos de la Nueva Granada. Bogotá, Colombia: Editorial Incunables.

El Escudo. (2 de septiembre de 1905). Higiene pública. El Escudo, s.p.

El Nuevo Tiempo. (16 de marzo de 1909a). Decreto número 286 (13 de marzo de 1909) por el cual se declara en estado de sitio la ciudad de Bogotá. El Nuevo Tiempo, s.p.

El Nuevo Tiempo. (16 de marzo de 1909b). Decreto número 288 (13 de marzo de 1909) por el cual se incorpora la Policía Nacional en el Ejército de la República. El Nuevo Tiempo, s.p.

El Nuevo Tiempo. (3 de julio de 1909c). Notas. El Nuevo Tiempo, s.p. 
El Reporter. (24 de mayo de 1905a). Obras que juzgamos de imperiosa necesidad en nuestra capital. El Reporter, s.p.

El Reporter. (30 de mayo de 1905b). Decreto número 24 (mayo 23 de 1905). El Reporter, s.p.

Ewen, S. (2015). What is Urban History? Cambridge, UK: Polity Press.

García-Mérou, M. (1989). Impresiones. Bogotá, Colombia: Academia Colombiana de Historia, Alcaldía Mayor de Bogotá e Instituto Distrital de Cultura y Turismo.

Gómez, A. (1938). Bogotá. Bogotá, Colombia: Editorial A. B. C.

La Fusión. (17 de julio de 1905). Circular. La Fusión, s.p.

Lemaître, E. (1994). Rafael Reyes. Biografía de un gran colombiano. Bogotá, Colombia: Editorial Norma.

Lepetit, B. (2001). Por Uma Nova História Urbana. São Paulo, Brasil: Editora da Universidade de São Paulo.

Martínez, C. (1978). Bogotá reseñada por cronistas y viajeros ilustres (1572-1948). Bogotá, Colombia: ESCALA.

Martínez, F. (2001). El nacionalismo cosmopolita. La referencia europea en la construcción nacional en Colombia, 1845-1900. Bogotá, Colombia: Banco de la República.

McGreevey, W. P. (1965). The economic development of Colombia (doctoral thesis). Massachussetts Institute of Technology, Massachussetts, United States.

Mejía, G. (2000). Los años del cambio. Historia urbana de Bogotá, 1820-1910. Bogotá, Colombia: CEJA.

Melo, J. O. (1989). La Constitución de 1886. En C. Calderón (Ed.), Nueva Historia de Colombia. I. Historia Política 1886-1946 (pp. 43-64). Bogotá, Colombia: Planeta Colombiana Editorial.

Melo, J. O. (1996). Colombia Hoy. Bogotá, Colombia: Imprenta Nacional de Colombia.

Mesa, D. (1980). La vida política después de Panamá. 1903-1922. En J. Jaramillo (Ed.), Manual de Historia de Colombia (pp. 80-176). Bogotá, Colombia: Instituto Colombiano de Cultura. 
Niño, C. (1991). Arquitectura y estado. Contexto y significado de las construcciones del Ministerio de Obras Públicas. Colombia, 1905-1960. Bogotá, Colombia: Instituto Colombiano de Cultura.

Ortega, A. (1924). Arquitectura de Bogotá. Bogotá, Colombia: Editorial Minerva.

Ortega, D. (1990). Cosas de Santafé de Bogotá. Bogotá, Colombia: Tercer Mundo Editores.

Ortiz, L. J. (2010). La Regeneración en Colombia (1878-1902). En D. Bonnet, M. J. LaRosa, y M. Nieto (Eds.), Colombia. Preguntas y respuestas sobre su pasado y su presente (pp. 231-253). Bogotá, Colombia: Ediciones Uniandes.

Ospina, L. (1987). Industria y protección en Colombia, 1810-1930. Medellín, Colombia: FAES.

Petre, F. L. (1906). The Republic of Colombia An Account of the country. Its people, its institutions and its resources. London, UK: Edward Stanford.

Posada, E. (2015). Colombia. La apertura al mundo. Tomo 3. 1880/1930. Madrid, España: Fundación MAPFRE.

Reclus, E. (1893). Colombia. Traducida y anotada con autorización del autor por F. J. Vergara y Velasco. Bogotá, Colombia: Papelería de Samper Matiz.

República de Colombia (1908a). División Territorial. Leyes, decretos y documentos. Bogotá, Colombia: Imprenta Nacional.

República de Colombia (1908b). Acto adicional y reformatorio de la Constitución Nacional y Leyes de 1908. Bogotá, Colombia: Imprenta Nacional.

República de Colombia (1911). Constitución de la República de Colombia. Bogotá, Colombia: Imprenta Nacional.

Reyes, E. (1986). Rafael Reyes. Memorias, 1850-1885. Bogotá, Colombia: Fondo Cultural Cafetero.

Reyes, R. (11 de junio de 1909b). Manifiesto. El Nuevo Tiempo, s.p.

Reyes, R. (1905). Decreto 509 de 1905 (Mayo 25). Recuperado de http://www.alcaldiabogota.gov.co/sisjur/normas/Norma1.jsp?i=13467\#0

Reyes, R. (22 de marzo de 1909a). Mensaje que el Excelentísimo señor Presidente de la República dirige a la Asamblea Nacional Constituyente y Legislativa. El Nuevo Tiempo, s.p. 
Röthlisberger, E. (1993). El Dorado. Bogotá, Colombia: Colciencias/Editorial Presencia.

Saffray, C. (1984). Viaje a la Nueva Granada. Bogotá, Colombia: Editorial Incunables.

Scruggs, W. L. (1900). The Colombian and Venezuelan Republics with Notes on Other Parts of Central and South America. Boston, United States: Little Brown and Company.

Suárez, A. M. (2006). La ciudad de los elegidos. Crecimiento urbano, jerarquización social y poder político. Bogotá, 1910-1950. Bogotá, Colombia: Editorial Guadalupe.

Suárez, A. M. (2008). Excavando el mito de la Atenas Suramericana. Reflexiones sobre la cultura bogotana de finales del siglo XIX. Revista Criterios. Cuadernos de Ciencias Jurídicas y Política Internacional, 1(1), 63-99.

Suárez, A. M. (2015a). Bogotá en la lógica de la Regeneración. Indagando sobre el papel cumplido por el Municipio en la conformación del Estado nacional a partir del análisis de la administración capitalina, 1886-1910 (tesis doctoral). Universidad de Buenos Aires, Buenos Aires, Argentina.

Suárez, A. M. (2015b). La imagen urbana de Bogotá. Reflexiones sobre el desarrollo histórico de la capital en virtud de su condición de "cerebro y corazón del país» a finales del siglo XIX y comienzos del XX. Quid 16, (5), 213-228.

Suárez, A. M. (2017a). La escenificación del poder en el espacio urbano capitalino. Bogotá, 1870-1910. La lógica urbana de Bogotá a finales del siglo XIX y comienzos del XX. Berlín, Alemania: PUBLICIA.

Suárez, A. M. (2017b). La construcción de la nación colombiana a la luz del modelo porfirista. Secuencia. Revista de historia y ciencias sociales, (98), 99-129.

Tenorio, M. (2012). Culturas y memoria. Manual Para ser historiador. Una invitación teórica y práctica para reescribir el pasado y reinventar el presente. Ciudad de México, México: Tusquets Editores.

Vélez, H. (1986). Rafael Reyes, o los inicios del Estado moderno en Colombia. Lecturas de Economía, (21), 59-80.

Vélez, H. (1989). Quinquenio, régimen político y capitalismo (1904-1909). En C. Calderón (Ed.), Nueva Historia de Colombia. I. Historia Política 1886-1946 (pp. 187214). Bogotá, Colombia: Planeta Colombiana Editorial.

Vélez, J. (1906). Informe presentado al Excmo. Sr. Presidente de la República por el Sr. D. Jorge Vélez Gobernador del Distrito Capital. Bogotá, Colombia: Imprenta Nacional. 
Vergara, J. M. (1936). Las tres tazas y otros cuadros de costumbres. Bogotá, Colombia: Editorial Minerva.

Villegas, S. (15 de agosto de 1953). La Biografía del General Reyes. Sábado. Semanario para todos al servicio de la Cultura y la Democracia en América, p. 3-4 y 8. 